\title{
A narrative review of socioeconomic disparities in the treatment of esophageal cancer
}

\author{
Aaron M. Delman ${ }^{1} \wedge$, Allison M. Ammann ${ }^{1}$, Kevin M. Turner ${ }^{1}$, Dennis M. Vaysburg ${ }^{1}$, \\ Robert M. Van Haren ${ }^{1,2}$
}

${ }^{1}$ Cincinnati Research in Outcomes and Safety in Surgery (CROSS), Department of Surgery, University of Cincinnati College of Medicine, Cincinnati, OH, USA; ${ }^{2}$ Division of Thoracic Surgery, Department of Surgery, University of Cincinnati College of Medicine, Cincinnati, OH, USA

Contributions: (I) Conception and design: AM Delman, RM Van Haren; (II) Administrative Support: RM Van Haren; (III) Provision of study materials or patients: AM Delman, AM Ammann, KM Turner, DM Vaysburg; (IV) Collection and assembly of data: All authors; (V) Data analysis and interpretation: All authors; (VI) Manuscript writing: All authors; (VII) Final approval of manuscript: All authors.

Correspondence to: Robert M. Van Haren, MD MSPH. 231 Albert Sabin Way ML-0558, Medical Sciences Building, Room 2472, Cincinnati, OH 45267, USA. Email: vanharrm@ucmail.uc.edu.

\begin{abstract}
The persistent challenges of disparities in healthcare have led to significantly distinct outcomes among patients from different racial, ethnic, and underserved populations. Esophageal Cancer, not unlike other surgical diseases, has seen significant disparities in care. Esophageal cancer is currently the 6th leading cause of death from cancer and the 8th most common cancer in the world. Surgical disparities in the care of patients with Esophageal Cancer have been described in the literature, with a prevailing theme associating minority status with worse outcomes. The goal of this review is to provide an updated account of the literature on disparities in Esophageal Cancer presentation and treatment. We will approach this task through a conceptual framework that highlights the five main themes of surgical disparities: patient-level factors, provider-level factors, system and access issues, clinical care and quality, and postoperative outcomes, care and rehabilitation. All five categories play a complex role in the delivery of high-quality, equitable care for patients with Esophageal Cancer. While describing disparities in care is the first step to correcting them, moving forward, we should focus on developing effective interventions to mitigate disparities, policies linking disparities to quality-of-care metrics, and delivery system change to enable minority patients to more easily access high volume centers.
\end{abstract}

Keywords: Esophageal cancer; surgery; disparities

Submitted Oct 17, 2020. Accepted for publication Dec 31, 2020.

doi: $10.21037 /$ jtd-20-3095

View this article at: http://dx.doi.org/10.21037/jtd-20-3095

\section{Introduction}

Healthcare disparities are differences in outcomes that are seen across different racial, ethnic, and underserved populations. Not only are they are estimated to cost society $\$ 175$ billion in terms of lost life years, but they also continue to effect patient survival across diseases (1-4). The Institute of Medicine in its 2003 landmark report, Unequal Treatment:
Confronting Racial and Ethnic Disparities in Healthcare, concluded that racial and ethnic healthcare disparities occur in part due to historic and cotemporary social and economic inequality in the United States (5). Moreover, recent emphasis has been placed on eliminating structural racism in order to improve healthcare disparities (6). With this goal in mind, the following review will describe the most up to date

^ ORCID: 0000-0002-4037-909X. 
literature detailing disparities in esophageal cancer diagnosis and management.

Esophageal cancer (EC) is currently the $6^{\text {th }}$ leading cause of death from cancer and the 8 th most common cancer in the world (7). According to the 2019 data from the Surveillance, Epidemiology, and End Results (SEER) Program, the annual incidence in the United States is roughly 18,000 cases, with a current 5 -year survival under $20 \%$ (8). Surgical disparities have been described in the literature, with a prevailing theme associating minority status with worse outcomes (3,4,9-11). The diagnosis, management, and outcomes of patients with esophageal cancer is subject to these same truths (12-18). The scope of this review is to provide an updated account of the literature on disparities in esophageal cancer presentation and treatment. We will approach this task through the conceptual framework designed by Torain et al. that highlights five main themes of surgical disparities: patientlevel factors, provider-level factors, system and access issues, clinical care and quality, and postoperative outcomes, care and rehabilitation (4). We present the following article in accordance with the Narrative Review Reporting Checklist (available at: http://dx.doi.org/10.21037/jtd-20-3095).

\section{Methods}

This narrative literature review to describe the healthcare disparities in EC presentation and treatment was conducted through a literature search of PubMed for the following terms: healthcare disparities, esophageal cancer, inequality, and surgery. For an updated account, only articles published in the peer-review process after January 1st 2000 were included. In addition, investigations had to be conducted in the United States, published in the English language, and include qualitative, quantitative, or mixed methods in their methodology. Systematic reviews previously published were also included in this study.

\section{Patient-level factors}

The predominant histological subtype in the United States is adenocarcinoma (ACA), however, African Americans more commonly present with Squamous Cell Carcinoma (SCC) of the esophagus (18), which portends a worse prognosis (19). ACA accounts for $68 \%$ of esophageal cancers in non-Hispanic whites (NHW), but only $15 \%$ of EC in African Americans (20). The same pattern is seen in early stage disease: a SEER registry of 1522 patients with T0-T2 esophageal cancer demonstrated that $86 \%$ of African American patients were diagnosed with SCC, compared to only $27 \%$ of NHW patients (18). Additionally, African Americans diagnosed with SCC were found to have poorly differentiated histology in $40 \%$ of cases, which is also associated with worse survival (18).

Patients with SCC are more likely to be tobacco users ( $88 \%$ vs. $79 \%$ ) and heavy alcohol users ( $77 \%$ vs. $50 \%$ ), as compared to patients with ACA (21). It is well documented that SCC has a significantly worse survival than ACA, and subsequently African American males worse than NHW males (5-year OS: $18.1 \%$ vs. $10.4 \%$ ); and much of the literature attributes the difference in incidence to the associated risk factors for SCC $(22,23)$.

The primary risk factors associated with the development of SCC include: African American race, NHW women, smoking, alcohol, diet/nutrition, and genetic factors $(23,24)$. Individuals who eat nitrogenous compounds or have significant deficits in the intake of fruits and vegetables are at increased risk of SCC (24). In contrast, the primary risk factors associated with the development of ACA include: male, white race, gastroesophageal reflux disease (GERD), Barrett's Esophagus, obesity, and tobacco use (25-27).

African Americans are also more likely diagnosed with a more advanced stage of disease. SEER registry analysis has demonstrated that African Americans are less likely to be diagnosed with localized disease as compared to NHWs (20\% vs. 24\%) (28). A Michigan Tumor Registry review of 1,093 patients with EC demonstrated African Americans were more likely to have metastatic esophageal cancer than NHW patients, regardless of income or insurance status (29). The increased disease burden in African Americans at the time of diagnosis may be attributed barriers to healthcare coverage, access, and system utilization, as well as later recognition of symptoms by providers.

\section{Provider-level factors}

Provider level factors play a significant role in the disparities in outcomes of patients with EC through unconscious bias, lack of cultural competency, language usage, and lack of staffed and resourced facilities (30-32). Molena et al. analyzed which patients received high-quality care based on the National Comprehensive Cancer Network guidelines within two academic institutions and found that patients who were African American, from lower socio-economic status (SES), and had SCC tumor histology were more likely to receive low-quality care (32). They hypothesized 
that this was due to a lower amount of patients with SCC undergoing esophagectomy (32).

Similarly, multiple large database studies have established an association between African Americans, lower SES, and refusal of esophagectomy leading to worse outcomes (33-35). Rahouma et al. analyzed the NCDB from 2004-2014 and found identified $3.8 \%$ of patients who were recommended for surgery but refused (33). By multivariate analysis these patients were more likely to be: elderly, female, nonwhite, SCC histology, absence of insurance, lower income, and treated at nonacademic centers. The patients who refused esophagectomy had worse median survival (32 vs. 21 months, $\mathrm{P}<0.001)(33)$.

Qualitative research has suggested that discrepancies in cancer surgery adherence can stem from differences in patient-provider communication (36,37). In 2004, Johnson et al. found that surgeons can be more verbally dominant and less patient-centered in their approach to African American patients (30). Additionally, it has been demonstrated that implicit biases and previous cultural exposures affect whether or not patients receive surgery and what type of surgery is performed (38-42). African American and minority patients are less likely to receive surgery for non-small cell clung cancer, pancreatic cancer, prostate cancer, colon cancer, and esophageal cancer $(40,41,43,44)$.

\section{System \& access}

There are significant barriers to equitable care in esophageal cancer for patients from disadvantaged backgrounds, among them are patient education, family support structures, financial burden/employment and centralization. Lineback et al. found communication difficulties and difficulty with patient education more common in patients from low SES backgrounds (45). In addition, support structures are key to optimal patient outcomes. EC patients in a Michigan cancer registry found that single African American patients were the least likely to undergo esophagectomy, placing social support as a perceived barrier that some disadvantaged patients may further suffer from (46). The diagnosis of cancer places the patient under an immense financial burden, especially in patients from the lowest household income (47). Among cancer survivors, uninsured patients are significantly less likely to receive necessary medical care (48). Furthermore, cancer survivors are more likely to be unemployed than healthy controls (33.8\% vs. 15.2\%), a burden most felt on those from disadvantaged backgrounds (49). Specifically, one study of EC survivors found that $33.3 \%$ of patients from low
SES were unemployed on follow up compared with only $2.6 \%$ of patients in high SES group (45).

Increasingly there has been a push towards centralization of care at high volume centers. However, this invariably leads to a new burden being placed on patients from low SES backgrounds. New York, New Jersey, and Pennsylvania patients from 1996-2006 experienced increased median travel distances for care, highest among them were patients with EC, with a $72 \%$ increased travel distance (50). Although, a review of the National Inpatient Sample demonstrated that centralization led to a decrease in post-operative mortality, proportionally the highest among disadvantaged groups defined as non-White race, public insurance, low household income (51). It appears that minority patients may derive the greatest benefit from treatment at high-volume centers. However, barriers such as distance traveled and cost may prevent them from having access to these facilities.

Barrett's esophagus is a known risk factor for esophageal ACA (52). In patients with increased risk for ACA (males, age $>50$, white race, GERD, elevated BMI, hiatal hernia, intra-abdominal distribution of fat), screening for Barrett's esophagus is recommended (53). SCC, on the other hand, has no established screening guidelines. African American men with exposure to alcohol and tobacco have squamous cell carcinoma rates approaching those of esophageal adenocarcinoma in non-Hispanic white men with reflux, a population for whom screening is advocated by AGA guidelines (20). It is possible that this lack of screening also contributes to later detection and therefore poorer prognosis of EC in African Americans.

\section{Clinical care \& quality}

Treatment selection in patients with newly diagnosed EC is highly personalized, best made by a multidisciplinary team due to its complexity (1). Treatment options include surgery, chemoradiation, and multimodality treatment (54). Treatment selection is highly dependent upon the stage at presentation, histology and fitness of the patient, among other factors; however, it is also dependent upon age, race and SES $(55,56)$.

Chemoradiation is part of the multimodal definitive therapy for locally advanced EC $(54,57,58)$. However, access to chemoradiation is not uniform. McClellaand et al. noted African Americans, American Indians, Hispanic Americans and Appalachian patients all had decreased access to radiation for across many different malignancies $(59,60)$. Decreased access to radiation therapy among African- 
Americans was independent of SES. Specifically in EC, Merkow et al. demonstrated lower utilization of neoadjuvant chemoradiation in patients greater than 75 years old, Medicare insurance status, increased comorbidities and stage II disease (61).

Disparities within surgery have been well described. African Americans undergo surgery at significantly lower rates than NHW patients in the SEER database $(18,62)$ and the National Cancer Database (NCDB). $(12,13,63)$ Savitch et al. found that matched African American patients were less likely to undergo surgery for all stages than NHW patients (12). Dong et al. demonstrated that only $10.8 \%$ of African American patients underwent surgery compared to $22.8 \%$ of non-Hispanic whites $(\mathrm{P}<0.001)$, after correction for stage of presentation (62). African American patients with locoregional disease more likely received radiation as sole therapy and were less likely to undergo surgery, leading to negative effects on survival (18). Furthermore, single African American patients were the least likely to receive esophagectomy and the most likely to refuse treatment in one study of the Michigan Cancer Registry, highlighting a need for improved patient centered education (46). Patients with EC studied in the NCDB who were uninsured or living in areas with lower education levels were also less likely to undergo surgery (13).

Decreased rates of surgical management of localized EC is also a major contributor to lower overall survival in African American patients (63-65). Several suggestions have been made for this disparity including unequal access to healthcare, and practice patterns resulting in decreased evaluation by qualified surgeons $(18,63,64)$. In addition, many of the recently performed studies utilizing the SEER registry have shown that the difference in survival rates disappeared after adjusting for receipt of a cancer-directed surgery (18,63-65). This further supports the theory that decreased rate of surgery in non-white populations is a major contributor to higher mortality rates. Interestingly, Taioli et al. utilizing the SEER database, concluded that the 1-year mortality for African Americans who received a cancer-directed surgery was significantly worse than NHW patients. This highlights differences in quality of health care delivered to minority patients and could be related to several factors affecting access to high volume centers (66).

\section{Postoperative outcomes, care and rehabilitation}

Operative outcomes are worse when complex cancer is performed at low volume centers $(51,67)$. Several studies have shown that esophagectomy at high-volume hospitals $(\geq 20$ esophagectomies/year) are associated with a significant reduction in mortality when compared to esophagectomy at low-volume hospitals $(4.9 \%$ vs. $18 \%)(67,68)$. Several patient-related factors have been shown to be associated with receiving cancer-surgery at a low volume hospitals and these include non-white status, non-private insurance, increased comorbidities, and nonelective admission (67). In particular, African American patients have been shown to be less likely to receive care at high volume centers (69). Al-Refaie et al. showed almost $90 \%$ of African American patients received esophagectomy at a low-volume hospital (67). Following esophagectomy, Rehmani et al. showed that African American patients had higher mortality rates at both low and highvolume centers when compared with NHWs. Furthermore, failure to rescue was higher for African Americans compared to NHW patients, and this was related to esophagectomy at low-volume hospitals (16,70).

When assessing disparities in neoadjuvant chemoradiation (CRT), a recent paper by Levinsky et al. found that patients undergoing delayed esophagectomy (defined as esophagectomy after 90 days from CRT) were more likely to be African American and of lower SES. This is likely owing to healthcare systems and social barriers to access affecting timely EC treatment in African American patients (71).

\section{Where we go from here}

EC is associated with significant disparities in care, and meaningful progress in reducing them has been limited $(2,72)$. It is evident that there are significant contributions from patient, provider, system, clinical care, and postoperative care in the delivery of health care to minority patients. Moving forward, we should focus on developing effective interventions to mitigate disparities, policies linking disparities to quality of care metrics, and delivery system change to enable minority patients to more easily access high volume centers (73). Specifically, further qualitative research into provider-level factors such as patient and provider communication, and policies to reward and incentivize high-quality care for minority patients are actionable directions for the future.

\section{Acknowledgments}

Funding: None. 


\section{Footnote}

Provenance and Peer Review: This article was commissioned by the Guest Editors (Virginia Litle and Kei Suzuki) for the series "Socioeconomic Disparities in the Treatment of Thoracic Malignancies" published in Fournal of Thoracic Disease. The article has undergone external peer review.

Reporting Checklist: The authors have completed the Narrative Review Reporting Checklist. Available at: http:// dx.doi.org/10.21037/jtd-20-3095

Conflicts of Interest: The authors have completed the ICMJE uniform disclosure form (available at http://dx.doi. org/10.21037/jtd-20-3095). The series "Socioeconomic Disparities in the Treatment of Thoracic Malignancies" was commissioned by the editorial office without any funding or sponsorship. Dr. Van Haren reports personal fees from Intuitive Surgery, during the conduct of the study. The authors have no other conflicts of interest to declare.

Ethical Statement: The authors are accountable for all aspects of the work in ensuring that questions related to the accuracy or integrity of any part of the work are appropriately investigated and resolved.

Open Access Statement: This is an Open Access article distributed in accordance with the Creative Commons Attribution-NonCommercial-NoDerivs 4.0 International License (CC BY-NC-ND 4.0), which permits the noncommercial replication and distribution of the article with the strict proviso that no changes or edits are made and the original work is properly cited (including links to both the formal publication through the relevant DOI and the license). See: https://creativecommons.org/licenses/by-nc-nd/4.0/.

\section{References}

1. Turner A. The Business Case for Racial Equity: A Strategy for Growth. WK Kellogg Foundation 2018.

2. Haider AH, Scott VK, Rehman KA, et al. Racial disparities in surgical care and outcomes in the United States: a comprehensive review of patient, provider, and systemic factors. J Am Coll Surg 2013;216:482-92.e12.

3. de Jager E, Levine AA, Udyavar NR, et al. Disparities in Surgical Access: A Systematic Literature Review, Conceptual Model, and Evidence Map. J Am Coll Surg 2019;228:276-98.
4. Torain MJ, Maragh-Bass AC, Dankwa-Mullen I, et al. Surgical Disparities: A Comprehensive Review and New Conceptual Framework. J Am Coll Surg 2016;223:408-18.

5. In: Smedley BD, Stith AY, Nelson AR, editors. Unequal Treatment: Confronting Racial and Ethnic Disparities in Health Care. Washington (DC), 2003.

6. Yearby R. Structural Racism and Health Disparities: Reconfiguring the Social Determinants of Health Framework to Include the Root Cause. J Law Med Ethics 2020;48:518-26.

7. Domper Arnal MJ, Ferrandez Arenas A, Lanas Arbeloa A. Esophageal cancer: Risk factors, screening and endoscopic treatment in Western and Eastern countries. World J Gastroenterol 2015;21:7933-43.

8. Surveillance, Epidemiology, and End Results (SEER) Program (www.seer.cancer.gov) SEER*Stat Database: Incidence - SEER Research Data, 9 Registries, Nov 2019 Sub (1975-2017) - Linked To County Attributes Time Dependent (1990-2017) Income/Rurality, 19692017 Counties, National Cancer Institute, DCCPS, Surveillance Research Program, released April 2020, based on the November 2019 submission [database on the Internet]2019. Accessed. Available online: https://seer. cancer.gov/statfacts/html/esoph.html

9. Chavers BM, Snyder JJ, Skeans MA, et al. Racial disparity trends for graft failure in the US pediatric kidney transplant population, 1980-2004. Am J Transplant 2009;9:543-9.

10. Haider AH, Weygandt PL, Bentley JM, et al. Disparities in trauma care and outcomes in the United States: a systematic review and meta-analysis. J Trauma Acute Care Surg 2013;74:1195-205.

11. Studying Surgical Disparities: It's Not All Black and White I SpringerLink. 2020.

12. Savitch SL, Grenda TR, Scott W, et al. Racial Disparities in Rates of Surgery for Esophageal Cancer: a Study from the National Cancer Database. J Gastrointest Surg 2021;25:581-92.

13. Schlottmann F, Gaber C, Strassle PD, et al. Disparities in esophageal cancer: less treatment, less surgical resection, and poorer survival in disadvantaged patients. Dis Esophagus 2020;33:doz045.

14. Asokan S, Sridhar P, Qureshi MM, et al. Presentation, Treatment, and Outcomes of Vulnerable Populations With Esophageal Cancer Treated at a Safety-Net Hospital. Semin Thorac Cardiovasc Surg 2020;32:347-54.

15. Gupta DR, Liu Y, Jiang R, et al. Racial Disparities, Outcomes, and Surgical Utilization among Hispanics 
with Esophageal Cancer: A Surveillance, Epidemiology, and End Results Program Database Analysis. Oncology 2019;97:49-58.

16. Rehmani SS, Liu B, Al-Ayoubi AM, et al. Racial Disparity in Utilization of High-Volume Hospitals for Surgical Treatment of Esophageal Cancer. Ann Thorac Surg 2018;106:346-53.

17. Eng OS, Nelson RA, Konstantinidis I, et al. Disparities in survival after trimodality therapy for esophageal adenocarcinoma. Dis Esophagus 2018;31.

18. Greenstein AJ, Litle VR, Swanson SJ, et al. Racial disparities in esophageal cancer treatment and outcomes. Ann Surg Oncol 2008;15:881-8.

19. Siewert JR, Stein HJ, Feith M, et al. Histologic tumor type is an independent prognostic parameter in esophageal cancer: lessons from more than 1,000 consecutive resections at a single center in the Western world. Ann Surg 2001;234:360-7; discussion 368-9.

20. Ashktorab H, Kupfer SS, Brim H, et al. Racial Disparity in Gastrointestinal Cancer Risk. Gastroenterology 2017;153:910-23.

21. Ashktorab H, Nouri Z, Nouraie M, et al. Esophageal carcinoma in African Americans: a five-decade experience. Dig Dis Sci 2011;56:3577-82.

22. Faivre J, Trama A, De Angelis R, et al. Incidence, prevalence and survival of patients with rare epithelial digestive cancers diagnosed in Europe in 1995-2002. Eur J Cancer 2012;48:1417-24.

23. Zhang Y. Epidemiology of esophageal cancer. World J Gastroenterol 2013;19:5598-606.

24. Wheeler JB, Reed CE. Epidemiology of esophageal cancer. Surg Clin North Am 2012;92:1077-87.

25. Hvid-Jensen F, Pedersen L, Drewes AM, et al. Incidence of adenocarcinoma among patients with Barrett's esophagus. N Engl J Med 2011;365:1375-83.

26. Kubo A, Corley DA. Body mass index and adenocarcinomas of the esophagus or gastric cardia: a systematic review and meta-analysis. Cancer Epidemiol Biomarkers Prev 2006;15:872-8.

27. Oze I, Matsuo K, Ito H, et al. Cigarette smoking and esophageal cancer risk: an evaluation based on a systematic review of epidemiologic evidence among the Japanese population. Jpn J Clin Oncol 2012;42:63-73.

28. Siegel R, Ward E, Brawley O, et al. Cancer statistics, 2011: the impact of eliminating socioeconomic and racial disparities on premature cancer deaths. CA Cancer J Clin 2011;61:212-36.

29. Fitzgerald TL, Bradley CJ, Dahman B, et al.
Gastrointestinal malignancies: when does race matter? J Am Coll Surg 2009;209:645-52.

30. Johnson RL, Roter D, Powe NR, et al. Patient race/ ethnicity and quality of patient-physician communication during medical visits. Am J Public Health 2004;94:2084-90.

31. Cooper LA, Roter DL, Johnson RL, et al. Patient-centered communication, ratings of care, and concordance of patient and physician race. Ann Intern Med 2003;139:907-15.

32. Molena D, Mungo B, Stem M, et al. Does Quality of Care Matter? A Study of Adherence to National Comprehensive Cancer Network Guidelines for Patients with Locally Advanced Esophageal Cancer. J Gastrointest Surg 2015;19:1739-47.

33. Rahouma M, Harrison S, Kamel M, et al. Consequences of Refusing Surgery for Esophageal Cancer: A National Cancer Database Analysis. Ann Thorac Surg 2018;106:1476-83.

34. Naik KB, Liu Y, Goodman M, et al. Concurrent chemoradiotherapy with or without surgery for patients with resectable esophageal cancer: An analysis of the National Cancer Data Base. Cancer 2017;123:3476-85.

35. Parsons M, Lloyd S, Johnson S, et al. Refusal of local therapy in esophageal cancer and impact on overall survival. Ann Surg Oncol 2021;28:663-75.

36. McNair AGK, MacKichan F, Donovan JL, et al. What surgeons tell patients and what patients want to know before major cancer surgery: a qualitative study. BMC Cancer 2016;16:258.

37. White-Means SI, Osmani AR. Racial and Ethnic Disparities in Patient-Provider Communication With Breast Cancer Patients: Evidence From 2011 MEPS and Experiences With Cancer Supplement. Inquiry 2017;54:46958017727104.

38. Haider AH, Schneider EB, Sriram N, et al. Unconscious race and social class bias among acute care surgical clinicians and clinical treatment decisions. JAMA Surg 2015;150:457-64.

39. Haider AH, Sexton J, Sriram N, et al. Association of unconscious race and social class bias with vignettebased clinical assessments by medical students. JAMA 2011;306:942-51.

40. Shavers VL, Brown ML, Potosky AL, et al. Race/ ethnicity and the receipt of watchful waiting for the initial management of prostate cancer. J Gen Intern Med 2004;19:146-55.

41. Suga JM, Nguyen DV, Mohammed SM, et al. Racial disparities on the use of invasive and noninvasive staging in patients with non-small cell lung cancer. J Thorac Oncol 2010;5:1772-8. 
42. Ricciardi R, Selker HP, Baxter NN, et al. Disparate use of minimally invasive surgery in benign surgical conditions. Surg Endosc 2008;22:1977-86.

43. Britton BV, Nagarajan N, Zogg CK, et al. Awareness of racial/ethnic disparities in surgical outcomes and care: factors affecting acknowledgment and action. Am J Surg 2016;212:102-8.e2.

44. Murphy MM, Tseng JF, Shah SA. Disparities in cancer care: an operative perspective. Surgery 2010;147:733-7.

45. Lineback CM, Mervak CM, Revels SL, et al. Barriers to Accessing Optimal Esophageal Cancer Care for Socioeconomically Disadvantaged Patients. Ann Thorac Surg 2017;103:416-21.

46. Paniagua Cruz A, Haug KL, Zhao L, et al. Association Between Marital Status and Racial Disparities in Esophageal Cancer Care. JCO Oncol Pract 2020;16:e498-e506.

47. Zafar SY, McNeil RB, Thomas CM, et al. Populationbased assessment of cancer survivors' financial burden and quality of life: a prospective cohort study. J Oncol Pract 2015;11:145-50.

48. Banegas MP, Dickerson JF, Kent EE, et al. Exploring barriers to the receipt of necessary medical care among cancer survivors under age 65 years. J Cancer Surviv 2018;12:28-37.

49. de Boer AG, Taskila T, Ojajärvi A, et al. Cancer survivors and unemployment: a meta-analysis and meta-regression. JAMA 2009;301:753-62.

50. Stitzenberg KB, Sigurdson ER, Egleston BL, et al. Centralization of cancer surgery: implications for patient access to optimal care. J Clin Oncol 2009;27:4671-8.

51. Schlottmann F, Strassle PD, Charles AG, et al. Esophageal Cancer Surgery: Spontaneous Centralization in the US Contributed to Reduce Mortality Without Causing Health Disparities. Ann Surg Oncol 2018;25:1580-7.

52. American Gastroenterological Association; Spechler SJ, Sharma P, et al. American Gastroenterological Association medical position statement on the management of Barrett's esophagus. Gastroenterology 2011;140:1084-91.

53. Shaheen NJ, Falk GW, Iyer PG, et al. ACG Clinical Guideline: Diagnosis and Management of Barrett's Esophagus. Am J Gastroenterol 2016;111:30-50; quiz 1.

54. Molena D, Stem M, Blackford AL, et al. Esophageal Cancer Treatment Is Underutilized Among Elderly Patients in the USA. J Gastrointest Surg 2017;21:126-36.

55. Bus P, Aarts MJ, Lemmens VE, et al. The effect of socioeconomic status on staging and treatment decisions in esophageal cancer. J Clin Gastroenterol 2012;46:833-9.
56. Moreno AC, Zhang N, Verma V, et al. Treatment disparities affect outcomes for patients with stage I esophageal cancer: a national cancer data base analysis. J Gastrointest Oncol 2019;10:74-84.

57. van Hagen P, Hulshof MC, van Lanschot JJ, et al. Preoperative chemoradiotherapy for esophageal or junctional cancer. N Engl J Med 2012;366:2074-84.

58. Bedenne L, Michel P, Bouché O, et al. Chemoradiation followed by surgery compared with chemoradiation alone in squamous cancer of the esophagus: FFCD 9102. J Clin Oncol 2007;25:1160-8.

59. McClelland S, 3rd, Perez CA. The pervasive crisis of diminishing radiation therapy access for vulnerable populations in the United States-part 3: HispanicAmerican patients. Adv Radiat Oncol 2018;3:93-9.

60. McClelland S, 3rd, Page BR, Jaboin JJ, et al. The pervasive crisis of diminishing radiation therapy access for vulnerable populations in the United States, part 1: African-American patients. Adv Radiat Oncol 2017;2:523-31.

61. Merkow RP, Bilimoria KY, McCarter MD, et al. Use of multimodality neoadjuvant therapy for esophageal cancer in the United States: assessment of 987 hospitals. Ann Surg Oncol 2012;19:357-64.

62. Dong J, Gu X, El-Serag HB, et al. Underuse of Surgery Accounts for Racial Disparities in Esophageal Cancer Survival Times: A Matched Cohort Study. Clin Gastroenterol Hepatol 2019;17:657-65.e13.

63. Revels SL, Morris AM, Reddy RM, et al. Racial disparities in esophageal cancer outcomes. Ann Surg Oncol 2013;20:1136-41.

64. Paulson EC, Ra J, Armstrong K, et al. Underuse of esophagectomy as treatment for resectable esophageal cancer. Arch Surg 2008;143:1198-203; discussion 203.

65. Steyerberg EW, Earle CC, Neville BA, et al. Racial differences in surgical evaluation, treatment, and outcome of locoregional esophageal cancer: a population-based analysis of elderly patients. J Clin Oncol 2005;23:510-7.

66. Taioli E, Wolf AS, Camacho-Rivera M, et al. Racial disparities in esophageal cancer survival after surgery. J Surg Oncol 2016;113:659-64.

67. Al-Refaie WB, Muluneh B, Zhong $W$, et al. Who receives their complex cancer surgery at low-volume hospitals? J Am Coll Surg 2012;214:81-7.

68. Metzger R, Bollschweiler E, Vallbohmer D, et al. High volume centers for esophagectomy: what is the number needed to achieve low postoperative mortality? Dis Esophagus 2004;17:310-4.

69. Sun M, Karakiewicz PI, Sammon JD, et al. Disparities 
in selective referral for cancer surgeries: implications for the current healthcare delivery system. BMJ Open 2014;4:e003921.

70. Liou DZ, Serna-Gallegos D, Mirocha J, et al. Predictors of Failure to Rescue After Esophagectomy. Ann Thorac Surg 2018;105:871-8.

71. Levinsky NC, Wima K, Morris MC, et al. Outcome of delayed versus timely esophagectomy after chemoradiation for esophageal adenocarcinoma. J Thorac Cardiovasc Surg 2020;159:2555-66.

72. Pitt SC, Merkow RP. Disparities Research-Mitigating Inequities in Surgical Care. JAMA Surg 2020;155:1012-4.

73. Gold M. Reducing Health Care Disparities: Where Are We Now? Mathematica Policy Research 2014; March 2014.
Cite this article as: Delman AM, Ammann AM, Turner KM, Vaysburg DM, Van Haren RM. A narrative review of socioeconomic disparities in the treatment of esophageal cancer. J Thorac Dis 2021;13(6):3801-3808. doi: 10.21037/jtd-20-3095 